\title{
Sandwich layered double hydroxides with graphene oxide for enhanced water desalination
}

\author{
Lili Wang ${ }^{1}$, Zijian Yuan ${ }^{1}$, Yuhui Zhang ${ }^{2}$, Wei Guo ${ }^{2 *}$, Xiaoming Sun ${ }^{*}$ and Xue Duan ${ }^{1}$
}

\begin{abstract}
Layered double hydroxides (LDHs) are a class of two-dimensional (2D) clay compounds that consist of positively charged host layers and exchangeable interlayer anions. The stability of their assemblies in aqueous environment is a challenge due to the extremely high hydrophilicity, which limits their use in membrane-based technologies. Here, we propose a graphene oxide (GO) armour protection strategy to substantially improve the stability of LDH membranes in aqueous solution. The sandwich structured GO/LDH/GO membranes (GLGMs) possess a negative-positive-negative charge heterojunction in the vertical direction that effectively blocks the transport of both cations and anions, i.e., $\mathrm{NaCl}$, but allows the permeation of water molecules. Following this mechanism, the GLGMs are used for desalination in a forward osmosis mode. A high rejection rate of over $95.2 \%$ for $\mathrm{NaCl}$ and water flux of over $2.1 \mathrm{~L} \mathrm{~m}^{-2} \mathrm{~h}^{-1}$ are achieved with simulated seawater.
\end{abstract}

Keywords: layered double hydroxides, layered 2D materials, nanofluidics, sandwich structures, ion transport, desalination

\section{INTRODUCTION}

2D-material-based membranes receive widespread attention for their facile fabrication [1], efficient chemical modification [2], and tunable channel size [3], which boost various applications in areas such as precise ionic sieving [4-6], energy conversion and storage [7], and other biomimetic nanofluidic devices [8-10]. To date, a variety of $2 \mathrm{D}$ nano-building-blocks are used for constructing layered membranes [11], for example, graphene oxide (GO) [12-14], transition metal dichalcogenides (TMDs) [1517], and metal-organic frameworks (MOFs) [18,19]. Abraham et al. [20] demonstrated how to control interlayer spacing in GO membranes by physical confinement and achieved accurate and tunable ion sieving. Jia et al. [16] reported a photoinduced active ion transport phenomenon through TMDs-based van-derWaals-like multilayer heterostructures for harnessing ionic power from the equilibrium electrolyte solution. However, most of these 2D nanosheets are negatively charged, which could not take full advantages of the electrostatic interactions between the inorganic salt ions and the 2D nanofluidic channels, particularly for applications, such as ionic sieving and water desalination. Combining both negatively and positively charged 2D nano- building-blocks is highly promising to fully expel both cations and anions in salt water [21].

Layered double hydroxides (LDHs) are a family of lamellar compounds with positively charged brucite-like layers and exchangeable anions, showing potential for rejecting cations to desalt [22-25]. However, in contrast to GO- or TMD-based membranes, which exhibit excellent stability in water, selfassembled LDH membranes would disintegrate spontaneously in aqueous solution due to their strong dispensability. This feature limits the application of $\mathrm{LDH}$-based materials in many membrane-based technologies [26-28]. Thus, to improve the stability of the LDH assembly in aqueous environment remains a challenge.

Herein, we propose a GO armour protection strategy to improve the stability of LDH membranes in aqueous solution. Through a three-step vacuum filtration of oppositely charged $\mathrm{GO}$ and $\mathrm{LDH}$ colloidal solutions, the $\mathrm{LDH}$ nanosheets are sandwiched into two GO layers, forming a heterogeneous trilayer GO/LDH/GO membrane (GLGM). The GLGM possesses a negative-positive-negative charge heterojunction in the vertical direction. In ionic solution, this structure effectively blocks the transport of salt ions (e.g., $\mathrm{NaCl}$ ) due to the strong electrostatic repulsions between the $2 \mathrm{D}$ nanofluidic channels and salt ions, but allows the permeation of water molecules. Following this mechanism, we further use the GLGMs with excellent water stability for desalination in a forward osmosis (FO) mode. A distinctly improved salt rejection rate of over $95.2 \%$ for $\mathrm{NaCl}$ is readily achieved compared with homogeneous GO-based membranes $(32.9 \%)$, and water flux of over $2.1 \mathrm{~L} \mathrm{~m}^{-2} \mathrm{~h}^{-1}$ is achieved using simulated seawater with multi-component ionic species.

\section{EXPERIMENTAL SECTION}

\section{Materials}

GO powder was purchased from XFNANO, China. $\mathrm{Co}\left(\mathrm{NO}_{3}\right)_{2}$. $6 \mathrm{H}_{2} \mathrm{O}, \mathrm{Al}\left(\mathrm{NO}_{3}\right)_{3} \cdot 9 \mathrm{H}_{2} \mathrm{O}$ and formamide were purchased from Sigma-Aldrich, USA. Other chemical reagents were analytical grade and used as received without further purification. Electrolyte solutions were prepared with MilliQ water $(18.2 \mathrm{M} \Omega \mathrm{cm})$.

\section{LDHs synthesis}

A co-precipitation method was applied by using $\mathrm{Co}\left(\mathrm{NO}_{3}\right)_{2} \cdot 6 \mathrm{H}_{2} \mathrm{O}$

\footnotetext{
${ }^{1}$ State Key Laboratory of Chemical Resource Engineering, Beijing Advanced Innovation Center for Soft Matter Science and Engineering, Beijing University of Chemical Technology, Beijing 100029, China

${ }^{2}$ CAS Key Laboratory of Bio-Inspired Materials and Interfacial Science, Technical Institute of Physics and Chemistry, Chinese Academy of Sciences, Beijing 100190, China

* Corresponding authors (emails: wguo@iccas.ac.cn (Guo W); sunxm@mail.buct.edu.cn (Sun X))
} 
and $\mathrm{Al}\left(\mathrm{NO}_{3}\right)_{3} \cdot 9 \mathrm{H}_{2} \mathrm{O}$ as the mixed metal salt solution and $\mathrm{NaOH}$ served as the precipitant, respectively. In a typical procedure, $\mathrm{Co}\left(\mathrm{NO}_{3}\right)_{2} \cdot 6 \mathrm{H}_{2} \mathrm{O}(0.0006 \mathrm{~mol})$ and $\mathrm{Al}\left(\mathrm{NO}_{3}\right)_{3} \cdot 9 \mathrm{H}_{2} \mathrm{O}(0.0002 \mathrm{~mol})$ were dissolved in $7 \mathrm{~mL}$ of deionized water with $3 \mathrm{~mL}$ of formamide, denoted as solution $\mathrm{A}$. $\mathrm{NaOH}(0.005 \mathrm{~mol})$ was dissolved in $10 \mathrm{~mL}$ of deionized water, denoted as solution $\mathrm{B}$. $\mathrm{NaNO}_{3}(0.0002 \mathrm{~mol})$ was dissolved in a mixture containing $4 \mathrm{~mL}$ of deionized water and $6 \mathrm{~mL}$ of formamide, denoted as solution C. The above solutions were ultrasounded for $5 \mathrm{~min}$ to be fully dissolved. Then, solutions A and B were simultaneously added into solution $\mathrm{C}$ dropwise with stirring at $80^{\circ} \mathrm{C}$, and maintained $\mathrm{pH}$ value of $\sim 10$. During the process, continuous $\mathrm{N}_{2}$ gas was purged to avoid the contamination of the atmospheric $\mathrm{CO}_{2}$. After $15 \mathrm{~min}$, the resulting precipitation was centrifuged at 3000 rpm for $10 \mathrm{~min}$ and washed with deionized water and anhydrous ethanol several times, followed by freeze-drying overnight. For further exfoliation, $50 \mathrm{mg}$ of the powder was mixed with $100 \mathrm{~mL}$ of degassed formamide in a conical beaker by sonication for $10 \mathrm{~min}$ and then stirred at a speed of $160 \mathrm{rpm}$ for $48 \mathrm{~h}$ under $\mathrm{N}_{2}$ atmosphere. Finally, the resulting pink, translucent colloidal suspension was centrifuged at $2000 \mathrm{rpm}$ for $10 \mathrm{~min}$ to remove the unexfoliated parts, and the CoAl LDH nanosheets were finally obtained.

\section{Membrane fabrication}

The GLGM was fabricated via a three-step vacuum filtration of GO and LDH dispersions (Fig. 1c). Firstly, the GO dispersion $\left(0.15 \mathrm{mg} \mathrm{mL}^{-1}\right)$ was filtrated through a polycarbonate membrane filter ( $47 \mathrm{~mm}$ in diameter, $100 \mathrm{~nm}$ pore size). The resulting GO membrane (GOM) was suction-dried overnight. Afterwards, $\mathrm{LDH}$ dispersion $\left(0.15 \mathrm{mg} \mathrm{mL}^{-1}\right)$ was filtrated onto the as-formed GOM. The resulting membrane was then suction-dried. Finally, another GO multi-layer was further deposited onto the membrane, forming the GLGM. To stabilize the membrane, the asprepared GLGMs were air-dried at ambient temperature for several hours, and then thermally annealed in an oven at $80^{\circ} \mathrm{C}$ for $24 \mathrm{~h}$.

\section{Characterization}

The surface charge properties of $\mathrm{GO}$ and $\mathrm{LDH}$ colloids $\left(0.15 \mathrm{mg} \mathrm{mL}^{-1}\right)$ were assessed by zeta potential measurements with a Malvern Zetasizer NanoZS90. The morphology of GO and $\mathrm{LDH}$ nanosheets were characterized with atomic force microscopy (Olympus, OLS4500). Transmission electron microscopy (TEM) was employed to obtain the micro morphology of LDH nanosheets. Scanning electron microscopy (SEM, Hitachi S4800) was used to characterize the cross-sectional microstructures of the GLGM. To detect the element distribution on the cross section of the GLGM, energy dispersive $\mathrm{X}$-ray spectroscopy (EDS) was employed. X-ray diffraction (XRD) characterization was carried out on a Bruker D8 Advance Focus diffractometer with a $\mathrm{Cu} \mathrm{Ka}$ radiation source to obtain the interlayer spacing. Nitrogen adsorption surface areas were measured by Brunauer-Emmett-Teller (BET) technique on a Micrometritics ASPS2020 analyzer.

\section{Electrical measurement}

For the current-voltage response in electrolyte solutions, a piece of testing membrane was mounted in a two-compartment electrochemical cell [29]. Electrolyte solution $\left(1 \times 10^{-4} \mathrm{~mol} \mathrm{~L}^{-1}\right)$ was filled in the two reservoirs. The tested membrane area was about $0.2 \mathrm{~mm}^{2}$. The transmembrane current was recorded with a source meter (Keithley 2636B) through $\mathrm{Ag} / \mathrm{AgCl}$ electrodes in each side.

\section{Desalination test}

Desalination was carried out using a U-shaped setup separated by a piece of testing membrane. The two compartments were referred as feed and draw. An aqueous sucrose solution $\left(1 \mathrm{~mol} \mathrm{~L}^{-1}\right)$ was placed on the draw side and $\mathrm{NaCl}$ solutions $(20.0 \mathrm{~mL})$ with different concentrations (ranged from $10^{-3}$ $1 \mathrm{~mol} \mathrm{~L}^{-1}$ ) were placed on the feed side, separately. The total membrane thickness could be tuned in the range of 0.75 $1.75 \mu \mathrm{m}$. The tested membrane area was about $177 \mathrm{~mm}^{2}$. Salt concentrations in feed and draw sides were then determined by inductively coupled plasma optical emission spectroscopy (ICPOES, Varian 710-OES). Salt rejection rate (\%) was calculated as 1 $-c_{\mathrm{GLGM}} / c_{\mathrm{PC}}$, where $c_{\mathrm{GLGM}}$ and $c_{\mathrm{PC}}$ are the ionic concentration at draw side in the presence and absence of the GLGM membrane [30], respectively. The water flux through the membrane was then calculated as $V /(t \times S)$, where $V$ denotes the increased volume of drawn water, $t$ stands for the desalination time, $S$ is the tested membrane area.

\section{RESULTS AND DISCUSSION}

\section{Membrane fabrication and characterization}

The LDH and GO dispersions $\left(0.5 \mathrm{mg} \mathrm{mL}^{-1}\right)$ are light pink and light brown, respectively. They can be stable for several weeks in lab conditions. Atomic force microscopy (AFM) characterization confirms that the lateral size of individual LDHs and GO nanosheet mostly ranges from 100 to $800 \mathrm{~nm}$, and their thicknesses are about 1.30 and $0.87 \mathrm{~nm}$, respectively (Fig. 1a). TEM (Fig. S1) further shows the hexagonal shape of the $\mathrm{LDH}$ nanosheets, whose lateral sizes are about $150 \mathrm{~nm}$ (Fig. 1a). Over the $\mathrm{pH}$ range of $3-10$, the $\mathrm{LDH}$ and $\mathrm{GO}$ nanosheets $\left(0.15 \mathrm{mg} \mathrm{mL}^{-1}\right)$ keep opposite surface charge properties (Fig. 1b). The zeta potentials are either above $+23 \mathrm{mV}$ for LDHs or below $-36 \mathrm{mV}$ for GO.

The tri-layer GLGM was fabricated by alternate deposition of oppositely charged GO and LDH colloids on a polymeric filter membrane (Fig. 1c). A mild thermal annealing process was further used to stabilize the membrane [31-33]. The resulting GLGM is flexible (Fig. 1d). SEM characterization on the cross section of the GLGM exhibits a clear laminar structure on the GO part and a compactly packed gravel-shaped structure on the LDH part (Fig. 1e). A clear boundary is also found between the $\mathrm{GO}$ and LDH parts.

Further EDS was carried out on the cross section of the GLGM (Fig. 1e). It unveils an obvious sandwich-like microstructure. From cobalt element mapping (Co, in green), one can see that the $\mathrm{LDH}$ part appears merely in the middle part of the membrane (cobalt is a constituent element of LDHs but not $\mathrm{GO}$ ). Carbon element mapping (C) shows that the GO parts appear in the upper and bottom surface layers of the heterogeneous membrane (carbon is a constituent element of GO but not LDHs). A clear interface in between (indicated by the arrows) reveals the $\mathrm{GO} / \mathrm{LDH} / \mathrm{GO}$ heterojunctions.

XRD characterization unveils that the GLGM exhibits two independent diffraction peaks at $10.4^{\circ}$ and $11.5^{\circ}$, indicative of the presence of LDHs $\left(11.5^{\circ}\right)$ and GO multilayers $\left(10.4^{\circ}\right)$ in the heterogeneous membrane (Fig. 1f). The diffraction peak at $10.4^{\circ}$ 

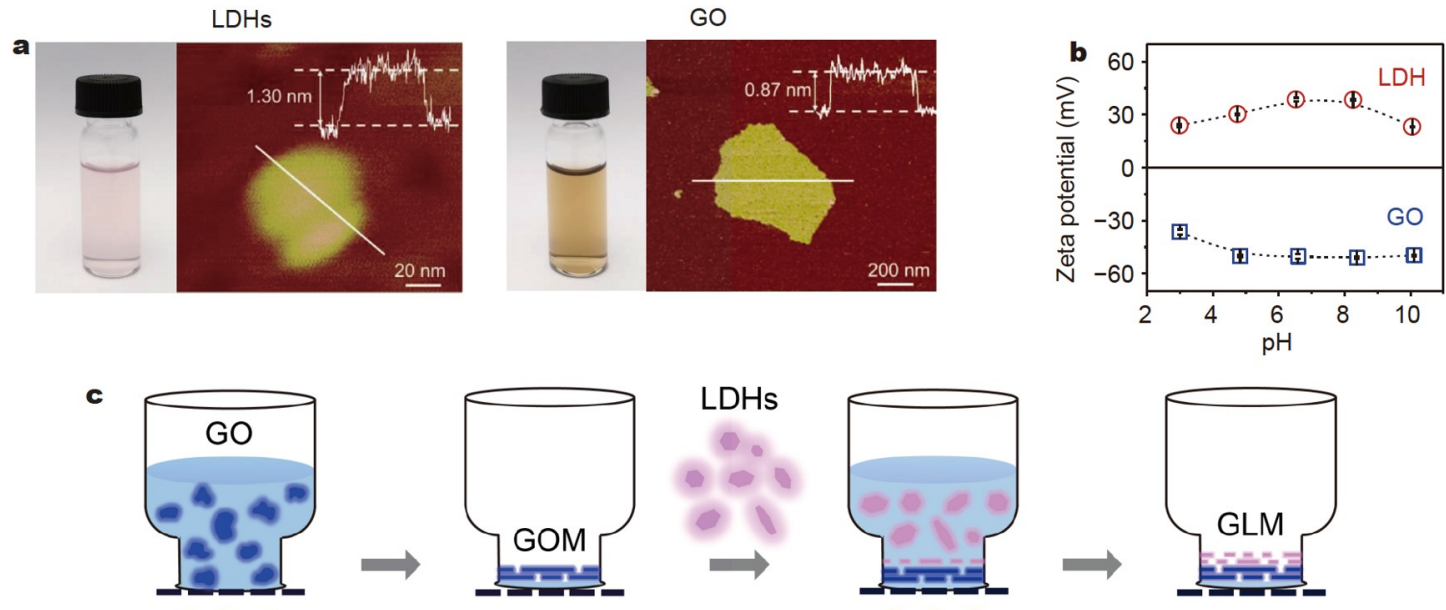

1 st step filtration
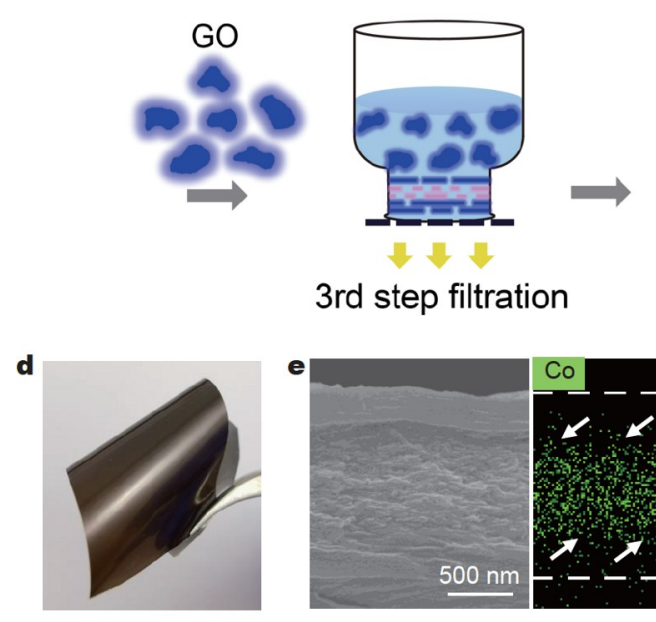

2nd step filtration

3rd step filtration
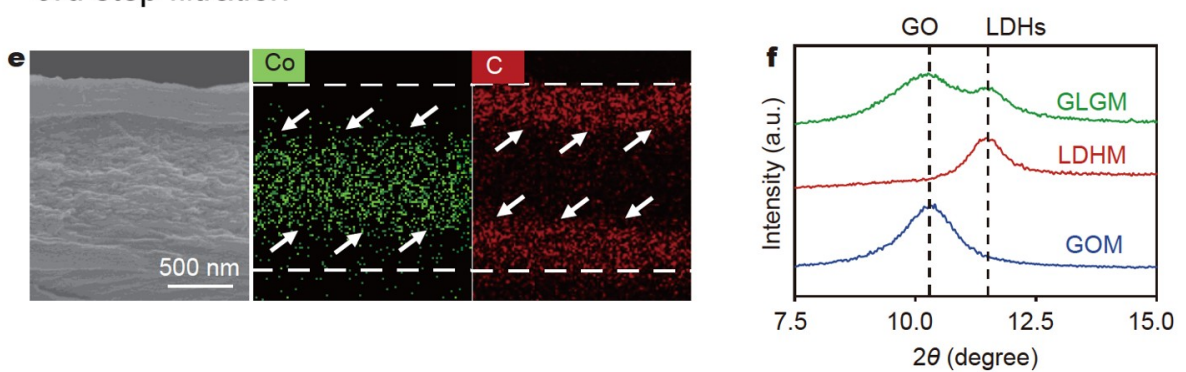

Figure 1 Membrane fabrication and characterization. (a) photographs of the LDH and GO dispersions $\left(0.5 \mathrm{mg} \mathrm{mL}^{-1}\right)$. Corresponding AFM characterization shows the lateral sizes of individual LDH and GO nanosheet mostly range from 100 to $800 \mathrm{~nm}$, and their thicknesses are about 1.30 and $0.87 \mathrm{~nm}$, respectively. (b) The zeta potentials of $\mathrm{LDH}$ and GO dispersions $\left(0.1 \mathrm{mg} \mathrm{mL}^{-1}\right)$ are above $+23 \mathrm{mV}$ and below $-36 \mathrm{mV}$ at varied pH, respectively. (c) Scheme of the threestep sequential filtration process for fabrication of GLGMs. (d) A photograph of the GLGM. (e) SEM observation on the cross section of the GLGM exhibits an obvious tri-layer microstructure. Corresponding EDS mapping of C and Co elements show a clear boundary between the middle and top (bottom) parts (indicated by white arrows). (f) XRD patterns of heterogeneous GLGM, and homogeneous LDHM and GOM. The two diffraction peaks suggest the presence of LDHs and GO multilayers in the heterogeneous membrane.

represents an interlayer spacing of $0.85 \mathrm{~nm}$ in GO multi-layers, which allows the permeation of most hydrated simple ions. The XRD patterns confirm the pure phase of the LDH particles. Considering the thickness of the triple atomic structure $(\sim 0.48 \mathrm{~nm})$, the effective channel height in LDH layers is about $0.29 \mathrm{~nm}[34,35]$, which cannot allow the permeation of hydrated simple salt ions or water molecules. To verify the presence of mass transport channels in LDH multi-layers, nitrogen adsorption-desorption isotherms was performed (Fig. S2). The pore size distribution was obtained using a Barrett-Joyner-Halenda model. The average pore diameter is about $3.7 \mathrm{~nm}$.

\section{Stability of the membranes in aqueous solution}

Fig. 2a shows the GLGM possesses an excellent stability in water at least for five days. In contrast, the LDH membranes (LDHMs) without the outer GO protection disintegrate in seconds right after being re-immersed in water. From the mass measurements, one can clearly see that, after being immersed in water, the mass loss of the GLGM can be almost ignored, in sharp contrast to that of the bare LDHMs (Fig. 2b).

XRD measurements on dry and wet GLGM further support its stability. As shown in Fig. $2 \mathrm{c}$, the diffraction peak at $11.5^{\circ}$, which is representative for the $\mathrm{LDH}$ layers, maintains at $11.5^{\circ}$ after being immersed in water. The lack of swelling in LDHMs is due to the strong electrostatic interactions generated by the high charge density of LDH nanosheets with the large amount of intercalated anions [36]. The interlayer spacing of GO expands from $0.85 \mathrm{~nm}\left(10.4^{\circ}\right)$ to $1.1 \mathrm{~nm}\left(8.0^{\circ}\right)$ upon hydration, but it is still stable in water due to thermal annealing treatment [31]. These XRD results suggest that the GO armour can prevent the $\mathrm{LDH}$ nanosheets from being re-dispersed in water.

\section{Vertical ion transport through heterogeneous GLGMs}

To investigate the ion transport properties of the heterogeneous membrane in the vertical direction, a piece of GLGM was mounted in a two-compartment electrochemical cell (Fig. 3a). 


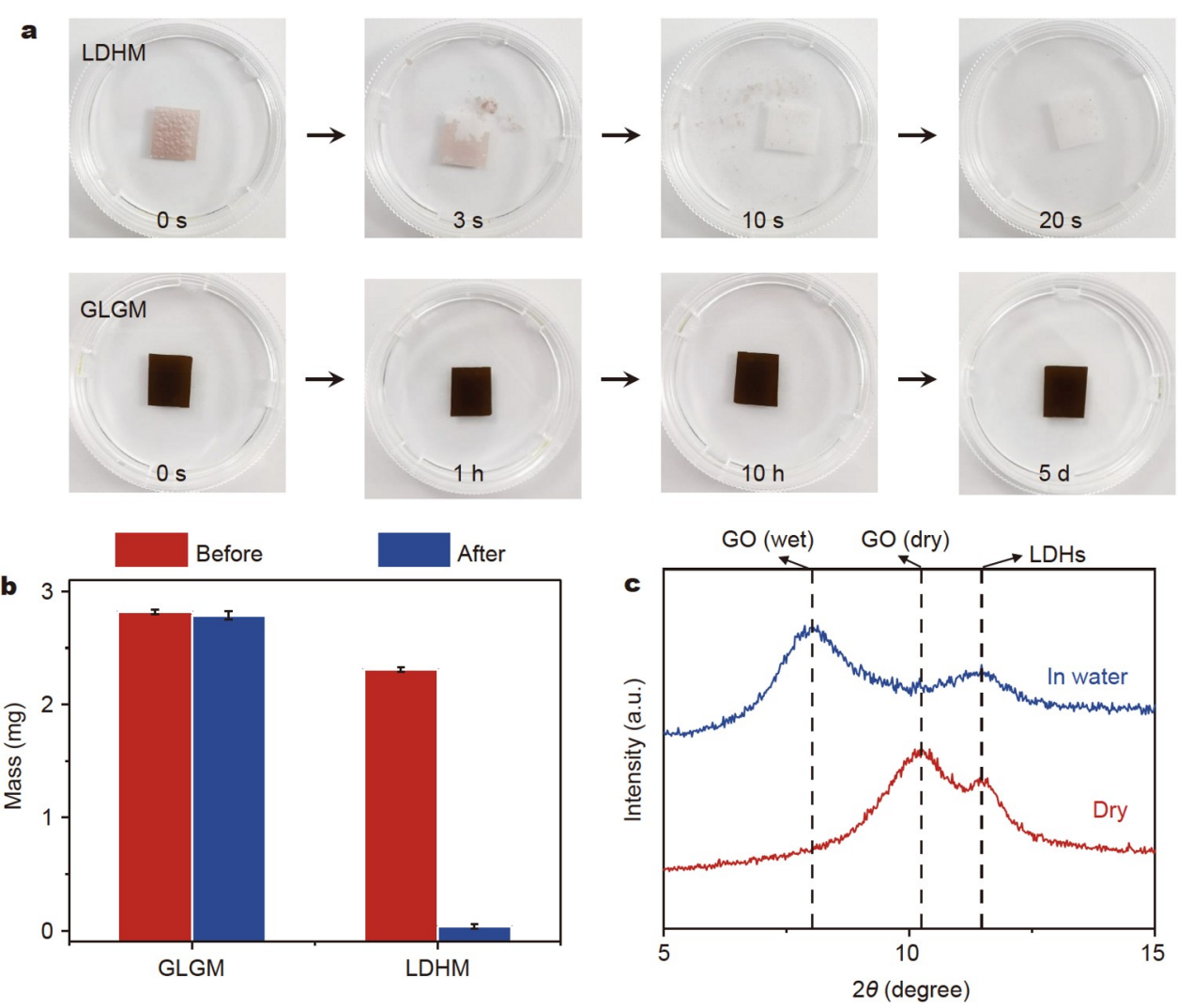

Figure 2 Stability of the membranes in aqueous solution. (a) Top: photos of homogeneous LDHM were taken after the membrane was ultrasonically treated at $30 \mathrm{~W}$ power for different time periods. Bottom: photos of heterogeneous GLGM were taken after the membrane was stored in water for at least 5 days. (b) The mass changes of GLGM and LDHM before and after water treatment. (c) XRD patterns of GLGM before and after water treatment.

Electrolyte solution $\left(2 \mathrm{~mL}, 1 \mathrm{mmol} \mathrm{L}{ }^{-1} \mathrm{KCl}\right)$ was filled in each reservoir. The tested membrane area was about $0.2 \mathrm{~mm}^{2}$. The total thickness of the tested membrane was $0.75 \mu \mathrm{m}$. The ionic current signals were recorded with a pair of $\mathrm{Ag} / \mathrm{AgCl}$ electrodes. Representative current-voltage response shows that ionic conductance through the GLGM is about 7 times lower than that through the homogeneous GOM with nearly identical thickness (Fig. 3b).

To verify the continuity of the ionic channels in the GLGM, we performed control experiments using diluted $\mathrm{HCl}$ $\left(1 \times 10^{-4} \mathrm{~mol} \mathrm{~L}^{-1}\right)$ as the electrolyte solution. In this case, proton acts as the major current carrier. Intriguingly, the proton conductivity in GLGM can be as high as that in the GOM (Fig. 3c). A similar salt-ion-blockade effect is also observed in other electrolyte solutions containing di- or multivalent salt ions (Fig. 3d). These evidences clearly support the presence of physically interconnected pathway for proton and water transport in GLGM, but not for salt ions.

In either salt ionic or $\mathrm{HCl}$ solutions, $\mathrm{LDH}$ and $\mathrm{GO}$ nanosheets keep their charge properties (Fig. 1b and Fig. S3). When cations reached the positive $\mathrm{LDH}$ layers, most of the adsorbed cations were blocked by electrostatic interactions rather than by sizebased ion exclusion. The high salt rejection is achieved by strong electrostatic interactions between salt ions and the charge heterogeneous membranes.

\section{D heterogeneous membrane for water desalination}

As an application, we further developed a GLGM-based device for water desalination in a forward osmosis mode (Fig. 4a). A piece of GLGM was mounted in a two-compartment electrochemical cell, where an aqueous sucrose solution $\left(1 \mathrm{~mol} \mathrm{~L}^{-1}\right)$ was placed on the draw side and salt solution on the feed side, respectively. The sucrose molecule with a large geometry size cannot freely permeate through the membranes, which generates a stable and high osmosis-driven pressure to draw both salt ions and water molecules from the feed side to the draw side [37]. Both the sodium and chloride ions are effectively blocked due to the strong electrostatic interactions produced by the vertical negative-positive-negative charge heterojunction. But the accommodating water is permeated to the side of sucrose solution.

As a visible proof-of-concept demonstration, $\mathrm{CuCl}_{2}$ solution $\left(0.1 \mathrm{~mol} \mathrm{~L}^{-1}\right)$ and sucrose solution $\left(1 \mathrm{~mol} \mathrm{~L}^{-1}\right)$ were used as the feed and draw solutions (Fig. 4a). After $8 \mathrm{~h}$, the color of feed solution becomes darker and the liquid level drops, while the liquid level of the draw solution increases and it is still colorless, showing the blockade of copper ions and penetration of water molecules. ICP-OES was used to independently measure the salt ionic concentration at draw side in the presence and absence of the GLGM membrane after the desalination process. Under a forward osmotic pressure, a remarkable salt rejection for $\mathrm{NaCl}$ is found at various concentrations from $10^{-3}$ to $1 \mathrm{~mol} \mathrm{~L}^{-1}$ (Fig. $4 \mathrm{~b}$ ). The thickness of the LDH layer was about $0.25 \mu \mathrm{m}$. The highest rejection rate approaches $81.9 \%$ in a moderate salt concentration of $10 \times 10^{-3} \mathrm{~mol} \mathrm{~L}^{-1}$. Meanwhile, as control experiments, we also checked the salt rejection with homogeneous GOM. Its rejection rate is distinctly lower than that of the GLGM (45\%-10\%).

Water flux is another important factor for desalination. As 

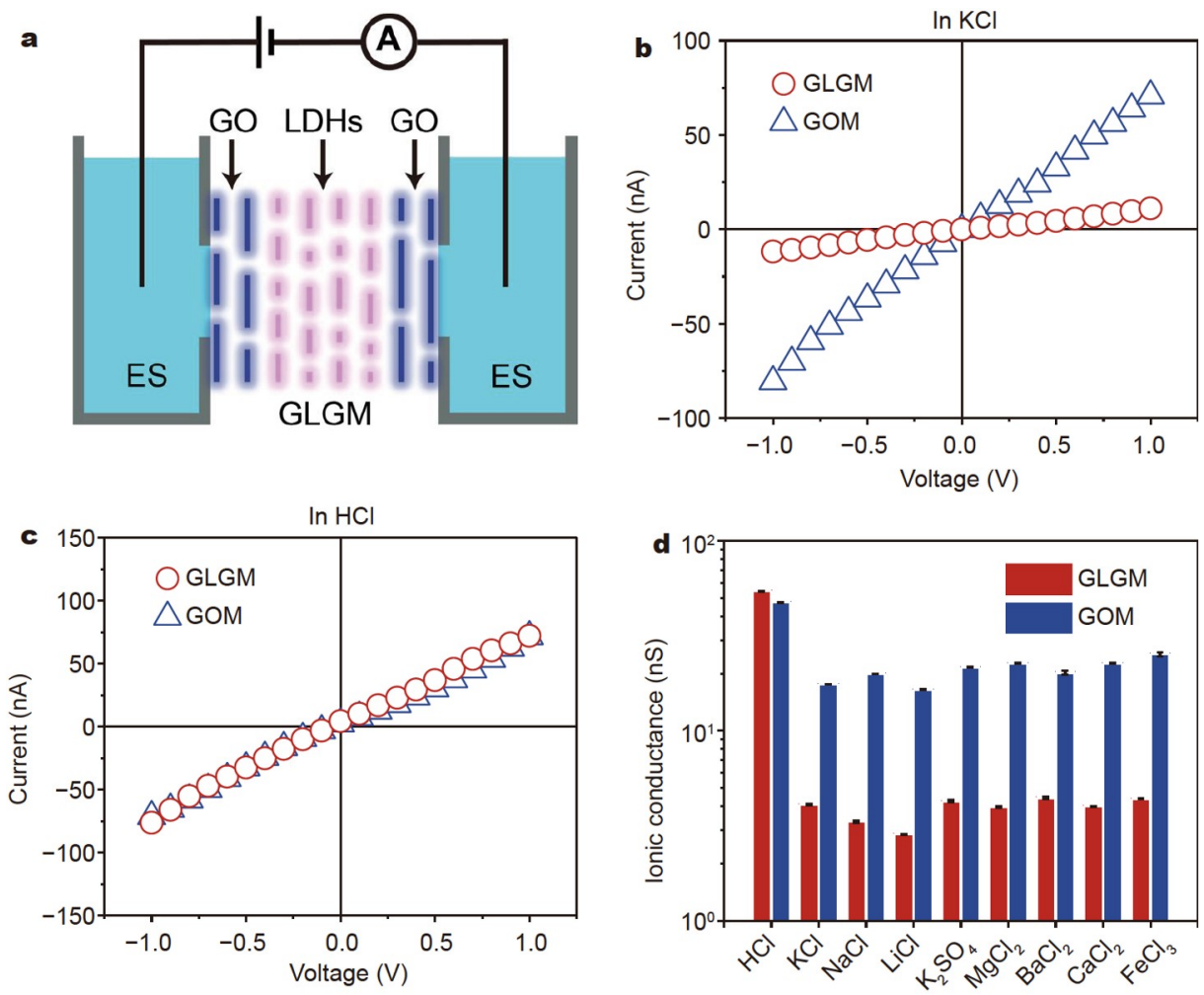

Figure 3 Vertical ion transport through the heterogeneous GLGM. (a) Scheme of the experiment. (b, c) Representative current-voltage responses in (b) KCl and (c) $\mathrm{HCl}$ solutions. $\mathrm{K}^{+}$and $\mathrm{Cl}^{-}$transport through GLGM are remarkably blocked, compared with that through $\mathrm{GOM}$. But in $\mathrm{HCl}$ solution, proton conductance through the GLGM and GOM is quite alike. (d) Similar salt-ion-blockade effect can be found in various salt solutions. The concentration of the salt or $\mathrm{HCl}$ solutions is $1 \times 10^{-4} \mathrm{~mol} \mathrm{~L}^{-1}$.
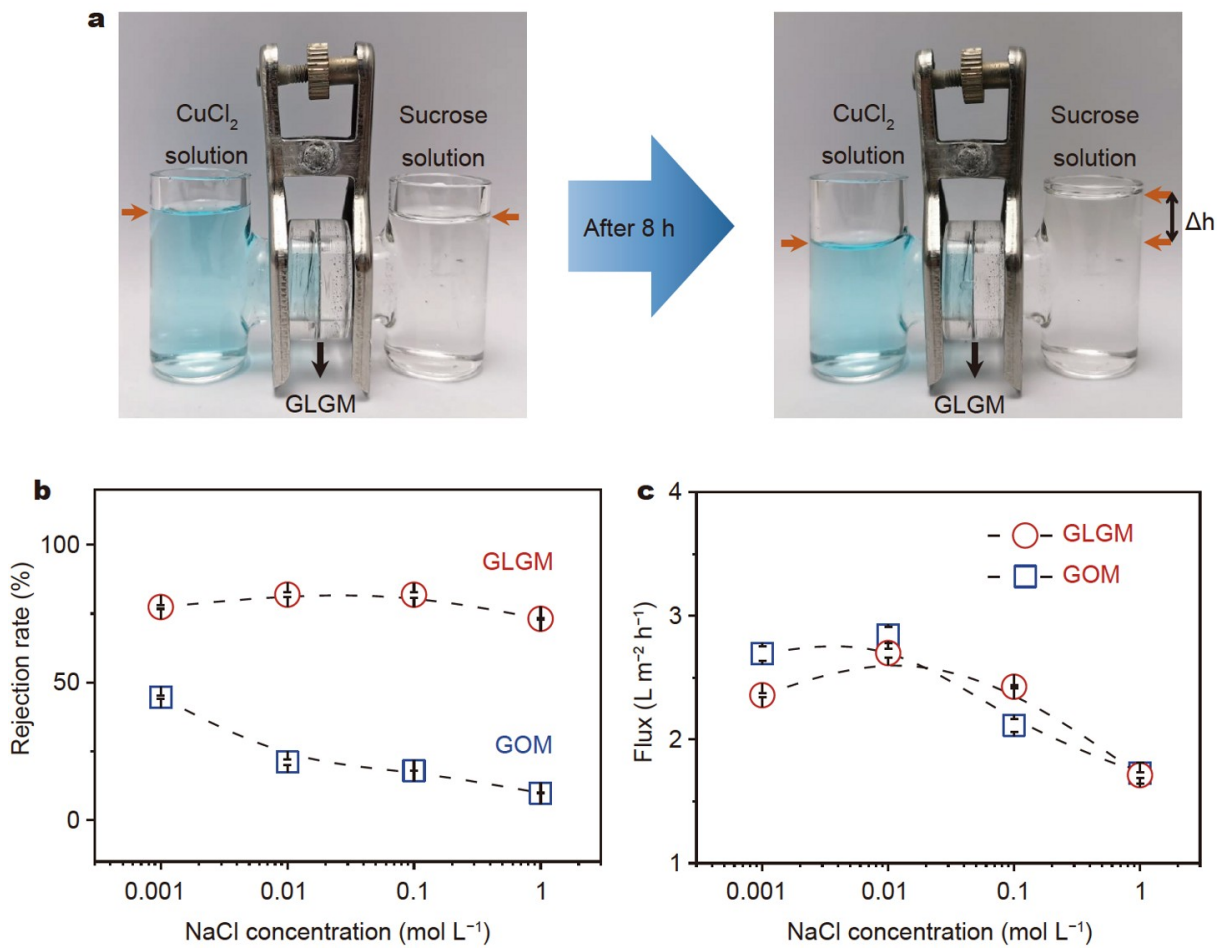

Figure 4 2D heterogeneous sandwich membrane (GLGM)-based desalination. (a) A photograph of the device. (b) Plot of the rejection properties of the GLGM (circular) and GOM (square) as a function of salt concentration measured after $24 \mathrm{~h}$. (c) The influence of salt ion concentration on the water flux through the GLGM (circular) and GOM (square). The water flux falls down with salt concentration. The draw solution is $1 \mathrm{~mol} \mathrm{~L}^{-1}$ sucrose solution, otherwise specifically mentioned. 
shown in Fig. 4c, the water flux falls down with the increasing salt content in feed solution due to the enhanced water-ion interaction in concentrated ionic solutions [38]. With similar thickness (about $0.75 \mu \mathrm{m}$ ), one can clearly see that the heterogeneous tri-layer GLGM does not sacrifice water flux, compared with the homogeneous GOM.

\section{Further discussion on the GLGM-based desalination}

We kept the thickness of the GO armour at about $250 \mathrm{~nm}$. As shown in Fig. 5a, the salt rejection rate shows a positive correlation with the thickness of the LDH layers. When the thickness approaches about $1 \mu \mathrm{m}$, the salt rejection rate keeps at a high level of about $94.3 \%$. Meanwhile, the water flux slightly drops down from 2.40 to $2.25 \mathrm{~L} \mathrm{~m}^{-2} \mathrm{~h}^{-1}$ with the increasing thickness of LDHs. To get an optimized performance, an effective LDH thickness of nearly $1 \mu \mathrm{m}$ is indispensible.

More intriguingly, the GLGM-based device can be used for water desalination in simulated seawater with multi-component ionic species (Fig. 5b). The composition of the simulated sea- water is shown in Table S1. For mono- and divalent ions, the rejection rates keep over $93 \%$, indicating the sandwich structure is generally repulsive to all salts of different concentrations in complex system. In contrast, the salt rejection rate obtained with homogeneous GOM is merely $27 \%-45 \%$ (Fig. S4). The water flux of the desalination setup over $2.1 \mathrm{~L} \mathrm{~m}^{-2} \mathrm{~h}^{-1}$ is similar to GOM.

We also tested the long-term performance of the GLGMbased device. The total membrane thickness was about $1.5 \mu \mathrm{m}$. The aqueous solution of draw side was collected every $6 \mathrm{~h}$ for further analysis. We also used $\mathrm{CuCl}_{2}$ solution $\left(0.1 \mathrm{~mol} \mathrm{~L}^{-1}\right)$ as the feed solution to get a visible demonstration. As shown in Fig. $5 c$, for all the tested water samples, the drawn solution is transparent, suggesting the separation of copper ions. The salt rejection rate keeps in the range of $89.0 \%-96.2 \%$ in the whole testing for $48 \mathrm{~h}$, and the water flux ranges from 1.97 to $2.11 \mathrm{~L} \mathrm{~m}^{-2} \mathrm{~h}^{-1}$ (Fig. $5 \mathrm{~d}$ ). It demonstrates the high stability of the sandwich membrane in addition to high rejection rate and universality.
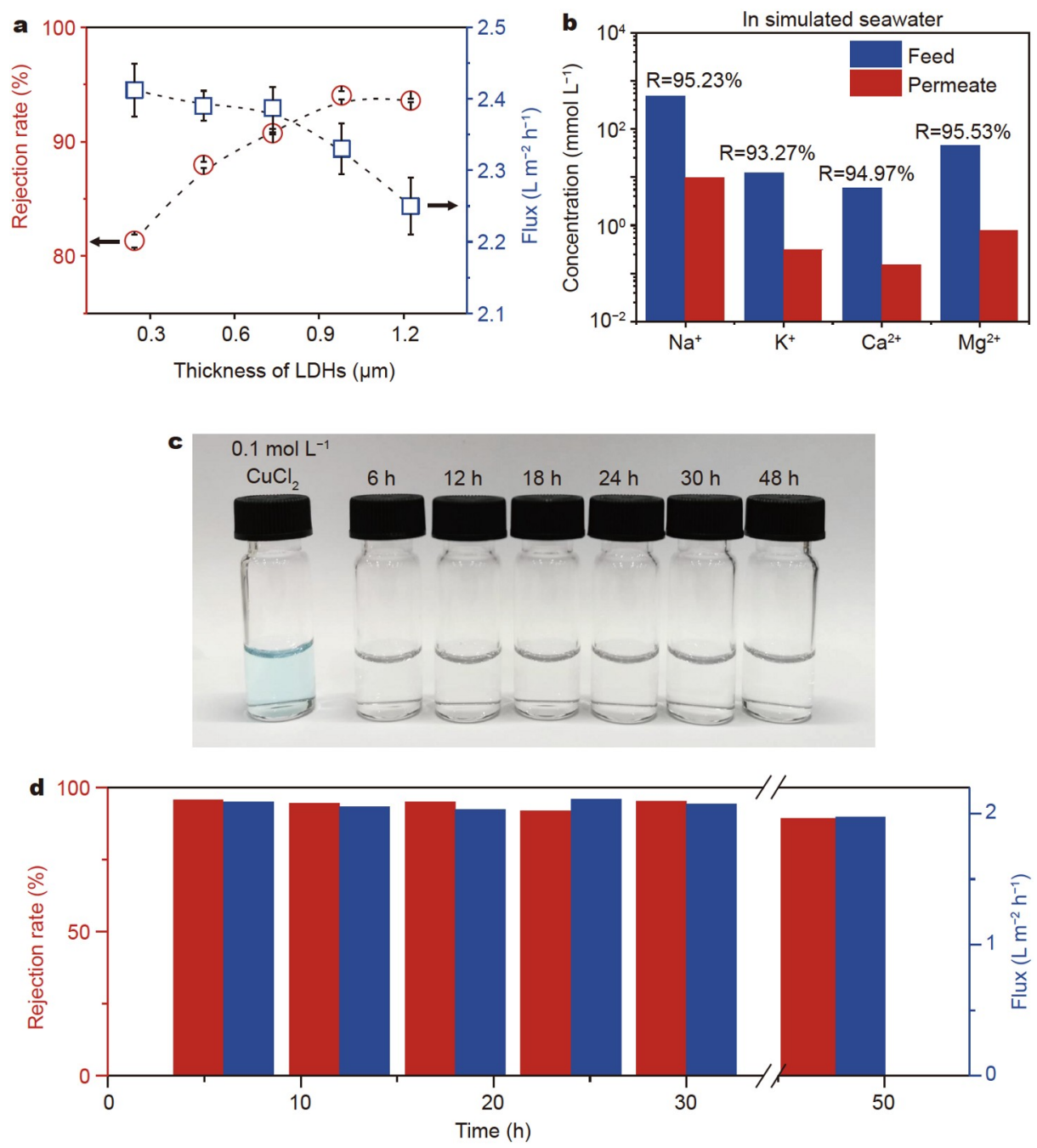

Figure 5 Further evaluation of the GLGM-based desalination. (a) Variations of rejection rate and water flux of the GLGM membranes as a function of membrane thickness measured after $24 \mathrm{~h}$. The concentrations of the salt solution and sucrose solution are $10 \times 10^{-3}$ and $1 \mathrm{~mol} \mathrm{~L} \mathrm{~L}^{-1}$, respectively. Otherwise specifically mentioned. (b) Rejection rates of $\mathrm{Na}^{+}, \mathrm{K}^{+}, \mathrm{Mg}^{2+}$ and $\mathrm{Ca}^{2+}$ through GLGM using simulated seawater as feed solution and sucrose solution $\left(1 \mathrm{~mol} \mathrm{~L}^{-1}\right)$ as draw solution, respectively. (c, d) Long-term test of the GLGM-based device. (c) A photograph of the feed solution $\left(0.1 \mathrm{~mol} \mathrm{~L}^{-1} \mathrm{CuCl}_{2}\right)$ and the drawn water collected at different time periods. The drawn water keeps transparent during the 48-h test. (d) The salt rejection rate and the corresponding water flux. The testing membranes are about $1.75 \mu \mathrm{m}$ thick. 


\section{CONCLUSIONS}

In conclusion, we demonstrate a $2 \mathrm{D}$-nanomaterial heterogeneous membrane protection strategy that LDH membrane protected by GO armour to improve the stability of the LDH membranes in aqueous solution. The heterogeneous membrane exhibits highly efficient desalination that effectively blocks the transport of simple inorganic salt ions for the strong electrostatic interactions between salt ions and the vertical negative-positivenegative charge heterojunction of GLGM, but enables the permeation of water molecules. Following this mechanism, we achieve a GLGM-based desalination device in a forward osmosis mode. Furthermore, the GLGMs show a high salt rejection rate of over $95.2 \%$ for $\mathrm{NaCl}$ and water flux of $2.1 \mathrm{~L} \mathrm{~m}^{-2} \mathrm{~h}^{-1}$ in the field of simulated seawater desalination with multi-component ionic species. In addition, the GLGM-based device can maintain excellent long-term performance, which can work properly for at least $48 \mathrm{~h}$ under lab conditions. We expect that the 2D heterogeneous membrane protection strategy will achieve a breakthrough in applications for sustainable water desalination and precise molecular sieving.

Received 29 June 2021; accepted 9 August 2021; published online 14 September 2021

1 Liu Z, Li Z, Xu Z, et al. Wet-spun continuous graphene films. Chem Mater, 2014, 26: 6786-6795

2 Wang X, Shi G. An introduction to the chemistry of graphene. Phys Chem Chem Phys, 2015, 17: 28484-28504

3 Yang X, Cheng C, Wang Y, et al. Liquid-mediated dense integration of graphene materials for compact capacitive energy storage. Science, 2013, 341: 534-537

4 Zheng Z, Grünker R, Feng X. Synthetic two-dimensional materials: A new paradigm of membranes for ultimate separation. Adv Mater, 2016, 28: 6529-6545

5 Sun C, Bai B. Molecular sieving through a graphene nanopore: nonequilibrium molecular dynamics simulation. Sci Bull, 2017, 62: 554-562

6 Joshi RK, Carbone P, Wang FC, et al. Precise and ultrafast molecular sieving through graphene oxide membranes. Science, 2014, 343: 752754

7 Cheng H, Zhou Y, Feng Y, et al. Electrokinetic energy conversion in self-assembled 2D nanofluidic channels with janus nanobuilding blocks. Adv Mater, 2017, 29: 1700177

8 Wang Y, Zhang H, Kang Y, et al. Voltage-gated ion transport in twodimensional sub-1 nm nanofluidic channels. ACS Nano, 2019, 13: 11793-11799

9 Guo W, Xia H, Cao L, et al. Integrating ionic gate and rectifier within one solid-state nanopore via modification with dual-responsive copolymer brushes. Adv Funct Mater, 2010, 20: 3561-3567

10 Cao L, Guo W, Wang Y, et al. Concentration-gradient-dependent ion current rectification in charged conical nanopores. Langmuir, 2012, 28: 2194-2199

11 Chen C, Wang J, Liu D, et al. Functionalized boron nitride membranes with ultrafast solvent transport performance for molecular separation. Nat Commun, 2018, 9: 1902

$12 \mathrm{Xu}$ WL, Fang C, Zhou F, et al. Self-assembly: A facile way of forming ultrathin, high-performance graphene oxide membranes for water purification. Nano Lett, 2017, 17: 2928-2933

13 Yuan Y, Gao X, Wei Y, et al. Enhanced desalination performance of carboxyl functionalized graphene oxide nanofiltration membranes. Desalination, 2017, 405: 29-39

14 Morelos-Gomez A, Cruz-Silva R, Muramatsu H, et al. Effective $\mathrm{NaCl}$ and dye rejection of hybrid graphene oxide/graphene layered membranes. Nat Nanotech, 2017, 12: 1083-1088

15 Ries L, Petit E, Michel T, et al. Enhanced sieving from exfoliated $\mathrm{MoS}_{2}$ membranes via covalent functionalization. Nat Mater, 2019, 18: 11121117
16 Jia $\mathrm{P}$, Wang L, Zhang Y, et al. Harnessing ionic power from equilibrium electrolyte solution via photoinduced active ion transport through vander-Waals-like heterostructures. Adv Mater, 2021, 33: 2007529

17 Wang Z, Tu Q, Zheng S, et al. Understanding the aqueous stability and filtration capability of $\mathrm{MoS}_{2}$ membranes. Nano Lett, 2017, 17: 72897298

18 Guo Y, Huang H, Li Z, et al. Sulfonated sub-nanochannels in a robust MOF membrane: Harvesting salinity gradient power. ACS Appl Mater Interfaces, 2019, 11: 35496-35500

19 Ang H, Hong L. Polycationic polymer-regulated assembling of 2D MOF nanosheets for high-performance nanofiltration. ACS Appl Mater Interfaces, 2017, 9: 28079-28088

20 Abraham J, Vasu KS, Williams CD, et al. Tunable sieving of ions using graphene oxide membranes. Nat Nanotech, 2017, 12: 546-550

21 Wen Q, Jia P, Cao L, et al. Electric-field-induced ionic sieving at planar graphene oxide heterojunctions for miniaturized water desalination. Adv Mater, 2020, 32: 1903954

22 Wang Q, Luo J, Zhong Z, et al. $\mathrm{CO}_{2}$ capture by solid adsorbents and their applications: current status and new trends. Energy Environ Sci, 2011, 4: 42-55

23 Qin Q, Wang J, Zhou T, et al. Impact of organic interlayer anions on the $\mathrm{CO}_{2}$ adsorption performance of $\mathrm{Mg}$ - $\mathrm{Al}$ layered double hydroxides derived mixed oxides. J Energy Chem, 2017, 26: 346-353

24 Li F, Tan Q, Evans DG, et al. Synthesis of carbon nanotubes using a novel catalyst derived from hydrotalcite-like Co-Al layered double hydroxide precursor. Catal Lett, 2005, 99: 151-156

25 Millange F, Walton RI, Lei L, et al. Efficient separation of terephthalate and phthalate anions by selective ion-exchange intercalation in the layered double hydroxide $\mathrm{Ca}_{2} \mathrm{Al}(\mathrm{OH})_{6} \cdot \mathrm{NO}_{3} \cdot 2 \mathrm{H}_{2} \mathrm{O}$. Chem Mater, 2000, 12: 1990-1994

26 Lee JH, Rhee SW, Jung DY. Ion-exchange reactions and photothermal patterning of monolayer assembled polyacrylate-layered double hydroxide nanocomposites on solid substrates. Chem Mater, 2006, 18: 4740-4746

27 Guth U, Brosda S, Schomburg J. Applications of clay minerals in sensor techniques. Appl Clay Sci, 1996, 11: 229-236

28 Yeh CN, Raidongia K, Shao J, et al. On the origin of the stability of graphene oxide membranes in water. Nat Chem, 2015, 7: 166-170

29 Wang L, Feng Y, Zhou Y, et al. Photo-switchable two-dimensional nanofluidic ionic diodes. Chem Sci, 2017, 8: 4381-4386

30 Hirunpinyopas W, Prestat E, Worrall SD, et al. Desalination and nanofiltration through functionalized laminar $\mathrm{MoS}_{2}$ membranes. ACS Nano, 2017, 11: 11082-11090

31 Ji J, Kang Q, Zhou Y, et al. Osmotic power generation with positively and negatively charged 2D nanofluidic membrane pairs. Adv Funct Mater, 2017, 27: 1603623

32 Wang L, Wen Q, Jia P, et al. Light-driven active proton transport through photoacid- and photobase-doped Janus graphene oxide membranes. Adv Mater, 2019, 31: 1903029

33 Zhang X, Wen Q, Wang L, et al. Asymmetric electrokinetic proton transport through 2D nanofluidic heterojunctions. ACS Nano, 2019, 13: 4238-4245

34 Gao R, Yan D. Fast formation of single-unit-cell-thick and defect-rich layered double hydroxide nanosheets with highly enhanced oxygen evolution reaction for water splitting. Nano Res, 2018, 11: 1883-1894

35 Wang L, Wang D, Dong XY, et al. Layered assembly of graphene oxide and $\mathrm{Co}-\mathrm{Al}$ layered double hydroxide nanosheets as electrode materials for supercapacitors. Chem Commun, 2011, 47: 3556-3558

36 Li L, Ma R, Ebina Y, et al. Positively charged nanosheets derived via total delamination of layered double hydroxides. Chem Mater, 2005, 17: 4386-4391

37 Qian Y, Shang J, Liu D, et al. Enhanced ion sieving of graphene oxide membranes via surface amine functionalization. J Am Chem Soc, 2021, 143: 5080-5090

38 Thomas M, Corry B. A computational assessment of the permeability and salt rejection of carbon nanotube membranes and their application to water desalination. Phil Trans R Soc A, 2016, 374: 20150020

Acknowledgements This work was financially supported by the National 
Natural Science Foundation of China (21975268) and China Postdoctoral Science Foundation (2019M660413). Wei Guo received a distinguished fellowship from the Youth Innovation Promotion Association of CAS.

Author contributions Wang $\mathrm{L}$ and Yuan $\mathrm{Z}$ performed the experiments; Wang L, Guo W, Sun X and Duan X wrote and revised the manuscript; Guo $\mathrm{W}$ and Sun $\mathrm{X}$ co-supervised the project. All authors contributed to the general discussion.

Conflict of interest The authors declare no conflict of interest.

Supplementary information Experimental details and supporting data are available in the online version of the paper.

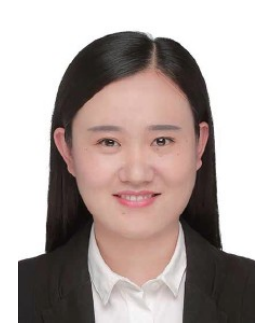

Lili Wang is a postdoctoral research fellow at the State Key Laboratory of Chemical Resource Engineering, College of Chemistry, Beijing University of Chemical Technology with Prof. Xue Duan and Prof. Xiaoming Sun. She received her $\mathrm{PhD}$ degree from the University of Science and Technology Beijing in 2018. Her current research focuses on designing intelligent 2D nanofluidic devices for energy- and environmentrelated applications.

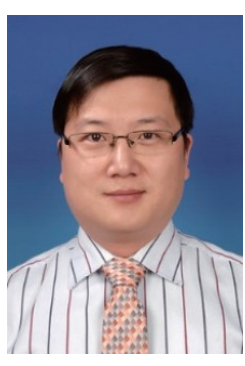

Xiaoming Sun obtained his $\mathrm{BSc}$ and $\mathrm{PhD}$ degrees from Tsinghua University in 2000 and 2005, respectively. He worked at Stanford University as a postdoc. Then, he joined Beijing University of Chemical Technology in 2008. His current research interest mainly focuses on the synthesis and separation of nanomaterials and improving the energy-related electrocatalysis process by tailoring the compositions, surface wettability and micro-/nanostructures.

\section{氧化石墨烯保护层稳定水滑石并用于海水淡化}

王丽丽 ${ }^{1}$, 袁子健 ${ }^{1}$, 张玉辉 ${ }^{2}$, 郭维 ${ }^{*}$, 孙晓明 $1^{*}$, 段雪 ${ }^{1}$

摘要 水滑石 $(\mathrm{LDHs})$ 是一类由带正电荷主体层板和可交换层间阴离子 组成的二维 (2D)粘土材料. 由于其具有极高的亲水性, 使得水环境下其 稳定性受到极大挑战，限制了其在膜技术中的应用. 在本文中，我们提 出了一种氧化石墨烯(GO)保护的策略, 利用氧化石墨烯保护层稳定水 滑石, 显著提高了水滑石膜在水溶液中的稳定性. 这种三明治结构的 $\mathrm{GO} / \mathrm{LDH} / \mathrm{GO}$ 膜(GLGMs) 在垂直方向上具有负-正-负电荷异质结, 有效 地阻止了阳离子和阴离子(例如 $\mathrm{NaCl}$ ) 的传输, 但允许水分子的渗透. 根 据这一机制, 我们将GLGMs用于正渗透模式下的脱盐. 对 $\mathrm{NaCl}$ 的截留 率高达 $95.2 \%$ 以上, 水通量为 $2.1 \mathrm{~L} \mathrm{~m}^{-2} \mathrm{~h}^{-1}$. 